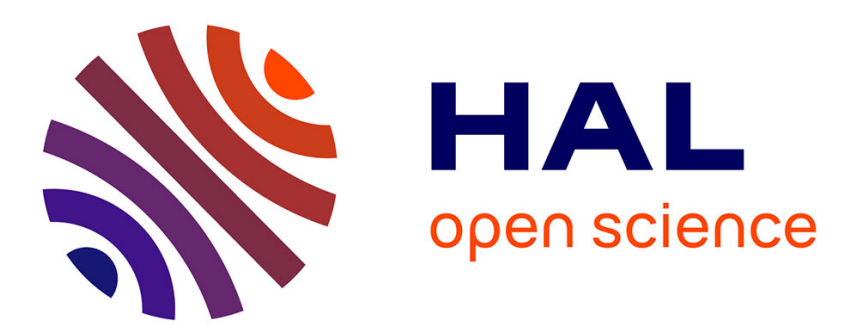

\title{
Characterization of wood filament in additive deposition to study the mechanical behavior of reconstituted wood products
}

Julien Gardan, Duy Cuong Nguyen, Lionel Roucoules, Guillaume Montay

\section{- To cite this version:}

Julien Gardan, Duy Cuong Nguyen, Lionel Roucoules, Guillaume Montay. Characterization of wood filament in additive deposition to study the mechanical behavior of reconstituted wood products. Journal of Engineered Fibers and Fabrics, 2016, 4 (11), pp.56-63. 10.1177/155892501601100408 . hal-02286154

\section{HAL Id: hal-02286154 \\ https://hal.science/hal-02286154}

Submitted on 13 Sep 2019

HAL is a multi-disciplinary open access archive for the deposit and dissemination of scientific research documents, whether they are published or not. The documents may come from teaching and research institutions in France or abroad, or from public or private research centers.
L'archive ouverte pluridisciplinaire HAL, est destinée au dépôt et à la diffusion de documents scientifiques de niveau recherche, publiés ou non, émanant des établissements d'enseignement et de recherche français ou étrangers, des laboratoires publics ou privés. 


\title{
Characterization of Wood Filament in Additive Deposition to Study the Mechanical Behavior of Reconstituted Wood Products
}

\author{
Julien Gardan $^{1,2}$, Duy Cuong Nguyen², Lionel Roucoules ${ }^{3}$, Guillaume Montay ${ }^{2}$ \\ ${ }^{1}$ EPF, Engineering School, Rosière-Près-Troyes France \\ ${ }^{2}$ ICD/LASMIS, UMR CNRS 6281, University of Technology of Troyes, Troyes France \\ ${ }^{3}$ Arts et Métiers Paris Tech, CNRS, LSIS, Aix-En-Provence France \\ Correspondence to: \\ Julien Gardan email: julien.gardan@epf.fr
}

\begin{abstract}
The use of materials derived from biomass is unavoidable to decrease environmental impact of products. The main advantage of the Additive Manufacturing (AM) concept is the ability to create complex geometries one layer at a time. The primary aim of this study was to create objects using reconstituted wood through manufacturing with low environmental impact. Wood can be converted into various derivatives allowing the introduction of sustainable material into the product lifecycle. This work uses an AM device adapted to a Computer Numerical Control (CNC) machine [1] to produce a reconstituted wood product by filament deposition. The first part assessed the deposit of wood pulp with a 3D printing head device, while the second part focuses on the characterization of microscopic structure of the material. Fiber morphology and mechanical properties of composite materials incorporating the filaments are characterized.
\end{abstract}

Keywords: Additive manufacturing, composite, rapid prototyping, wood pulp, fiber, mechanical characterization.

\section{INTRODUCTION}

Since the appearance of rapid prototyping, many different technologies have appeared on the market. There are several available technologies based on the additive machining concept [2]: stereolithography (SLA), photo-masking, Selective Laser Sintering (SLS), Fused Deposition Modeling (FDM) and 3D printing are a few examples. Research to date has focused mainly on the influence of part orientation, slicing strategy, internal optimized structure, matching internal patterns to improve cost, product quality, built time, etc. Additive Manufacturing (AM) or $3 \mathrm{D}$ printing has is well developed and currently offers several solutions using synthetic polymers such as acrylonitrile butadiene styrene (ABS), polyamides (PA) and others which can have negative environmental impact. Due to the evolution of rapid prototyping technologies, it has become possible today to obtain parts representative of mass production within a very short time [3]. Today, a balance between ecologically friendly materials, economic processing and mechanical properties of the final product is highly desirable [4].

The notion of "sustainable" products leads to the use of materials and manufacturing processes compatible with sustainable environment throughout the product lifecycle. The wood lifecycle includes some compounds which involve the wood-based panels such as plywood, particle board, fiber, etc. Woodbased products are of interest due to their economic, technical and environmental attributes.

A previous paper described the applications of additive manufacturing through a piston deposition which required an extrusion system [1]. This deposition system consists of a 3D printing head integrated into a Computer Numerical Control (CNC) machine instead of the end mill and can be used to produce a reconstituted wood product with ecological advantages. This research work describes the development of a wood pulp based on starch and beech wood and use of using the deposition system pictured in Figure 1(b) to extrude samples shown in Figure 2. This process creates a wood composite structure which includes fibers from the wood flour. Mechanical properties of the extruded specimens are characterized and a Design of Experiments (DOE) is used to optimize those properties [5]. 


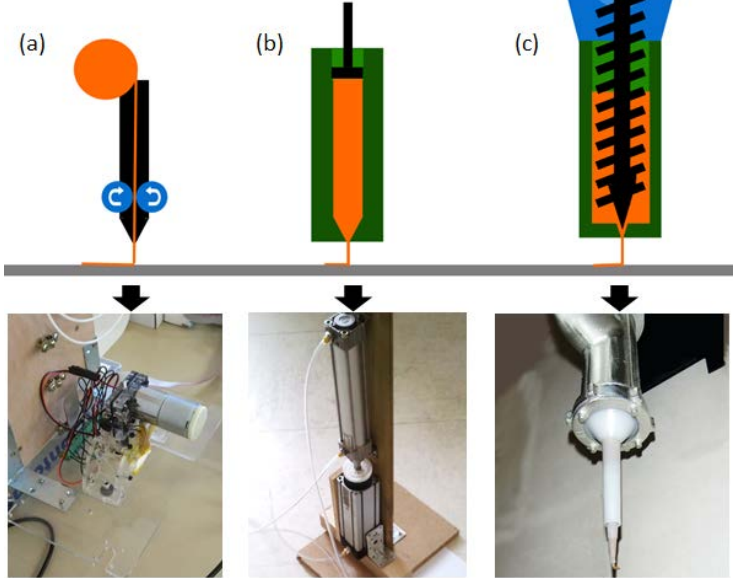

FIGURE 1. Overview of implemented technologies: a. Fused deposition; b. Piston deposition; c. Screw deposition.

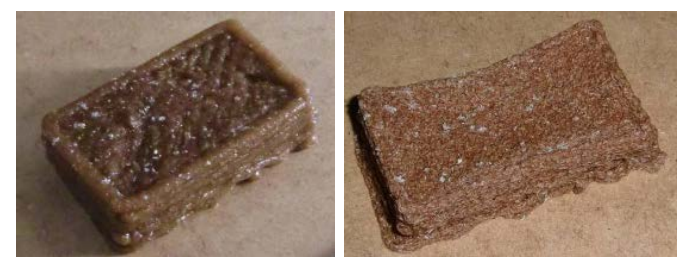

FIGURE 2. Test samples produced using wood pulp.

\section{MATERIALS AND PROCESSING}

Additive Manufacturing Technology

The first form of creating a three-dimensional object layer by layer using computer-aided design (CAD) was rapid prototyping, developed in the 1980's for creating models and prototype parts. Building up components layer by layer in such a manner is called rapid prototyping, rapid manufacturing, layer manufacturing, solid freeform fabrication or additive manufacturing. This technology allows the creation of printed parts beyond CAD models. Advantages offered by this technology to the product development process are time and cost reduction, human interaction, and consequently more efficient product development cycles. Increasingly, this technology is being used to manufacture finished products rather than prototypes [6].

The technique used most commonly is the Dough Deposition Modeling (DDM) which consists of individual processes deposit different doughs [2]. Some technologies based on FDM (Fused Deposition Modeling) printers use a syringe to deposit such materials as silicone, food dough or chocolate. A syringe based extrusion tool uses a linear stepper motor to control the syringe plunger position [7]. The
FDM technology was invented in the 1980s by Scott Crump [8,9]. Medical research uses this technology for the deposition of biomaterial and cells to realize a tissue structure. It presents a novel method for the deposition of biopolymers in high-resolution structures, using a pressure-activated microsyringe [10]. Other studies describe applications involving extrusion of a bio-based material using a piston and 3D printer head adapted on a CNC machine (Figure 1 (b)) to deposit a wood pulp based on wood flour, creating a reconstituted wood product $[1,5]$.

Currently the most widely used materials in FDM are ABS, polylactic acid (PLA), and PC (Polycarbonate). Compared to ABS, PLA is more sensitive to moisture and ultraviolet (UV) radiation, resulting in discoloration and loss of mechanical properties. To predict the mechanical behavior of FDM parts, it is critical to understand the material properties of the raw material, and the effect that FDM build parameters have on anisotropic material properties [11]. The disadvantages are that the resolution on the $z$ axis is low compared to other additive manufacturing process $(0.25 \mathrm{~mm})$, so if a smooth surface is needed a finishing process is required and it is a slow process sometimes taking days to build large complex parts [12]. FDM is the most widely used technology in desktop 3D printers and the less expensive professional printers.

Recently, with progress in material and enabling technology, many new AM techniques have emerged and been applied in fields such as rapid tooling/molding, direct formed usable parts, nano/micro-AM, and biomanufacturing [15]. Some studies use biomaterials in AM to realize 3D structures or products with degradable polymers such as polylactic acid (PLA) [13,14], but none use a material generated directly from biomass.

\section{Biomass Material: Wood}

Wood (or cellulose) is a biodegradable organic material which is more or less long term reintegrated into the natural carbon cycle. Wood takes part in the reduction of carbon dioxide emissions as an alternative to non-renewable materials, the latter leading to energy costs and other negative impacts to the ecosystem. The mechanical properties of wood are all the more interesting because they are directly related to the microscopic structure of the cell wall forming the wood fibers (composed of several layers of different thicknesses and made of microfibrils arranged helically and oriented in a specific angle for each species). 
This microfiber orientation is important to the mechanical behavior of material. Examination of wood fibers side by side shows that the antisymmetric inclination of the fibers increases the mechanical strength (like the synthetic composites by layer). The life cycle of wood includes certain compounds that involve all materials using wood material processed as main base, such as plywood, particle board, fiber, etc.

When wood and its by-products are cut or processed, the characteristics of the fiber cells and their provisions will change the properties of the final material [16]. Wood flour, on the other hand, is an unstructured material defined by a particle size distribution of small fibers. The development of reconstituted wood products by additive manufacturing is of interest due to a more positive impact on the environment than synthetic polymers.

\section{Wood Pulp and Processing}

The wood pulp is incorporated into the manufacturing process by a cold extrusion. The solidification time will be much longer than for other AM applications. However, the application addresses the goal of Ecodesign. In this experiment, beech flour from deciduous tree is used. It was obtained from J. Rettenmaier \& Soehne (JRS), under the name LIGNOCEL HB 120 (Table I). A Design of Experiment (DOE) using the following variables was employed:

- $\quad$ Grain sizes of beech flour: $40 \mu \mathrm{m}$ and 120 $\mu \mathrm{m}$

- $\quad$ Mass of beech flour: $20 \mathrm{~g}$ and $40 \mathrm{~g}$

- $\quad$ Mass of ether starch: $10 \mathrm{~g}$ and $40 \mathrm{~g}$

- $\quad$ Volume of demineralised water: $200 \mathrm{ml}$ and $300 \mathrm{ml}$

TABLE I. Wood flour properties HB 120.

\begin{tabular}{|c|c|c|c|}
\hline Name & Structure & Size & Density \\
\hline HB 120 & Fibrous & $40-120 \mu \mathrm{m}$ & $140-200 \mathrm{~g} / \mathrm{L}$ \\
\hline
\end{tabular}

A modified starch (Table II) was used to develop viscosity through crosslinking and binding properties at low temperatures or at normal heat in a waterlimited environment. Modified starch remains completely biodegradable. However, it should be noted that the nature of the starch as a natural substance decreases with the increasing use of etherification.
TABLE II. Modified starch.

\begin{tabular}{|c|c|c|}
\hline Name & Chemical area & F.additive \\
\hline Starch ether & Hydroxypropyl Starch & E 1440 \\
\hline
\end{tabular}

The tests were conducted with 3D printing head installed on a CNC machine to produce test specimens layer by layer. The manufacturing conditions are defined below:

- Filament diameter: $1.2 \mathrm{~mm}$

- Temperature: $20^{\circ} \mathrm{C}$

- Humidity: 60\% RH

- Extrusion piston: compressed air

- $\quad$ Extrusion speed : $1.3 \mathrm{~m} / \mathrm{min}$

An electric piston would offer a more stable extrusion, but the high sensitivity to humidity precluded its use. A Design Of Experiment (DOE) was previously implemented to optimize the wood pulp strength $[5,17,18]$. The study showed that the interactions of beech flour and starch have the highest effect on the wood pulp strength. The optimized tensile strength is reported in Table III.

TABLE III. Outcomes between mechanical tests and Design of Experiments.

\begin{tabular}{|c|c|}
\hline $\begin{array}{c}\text { Tensile strengh } \\
\text { (Mechanical) }\end{array}$ & $\begin{array}{c}\text { Tensile strengh } \\
\text { (DOE) }\end{array}$ \\
\hline $2,5 \mathrm{MPa}$ & $3,5 \mathrm{MPa}$ \\
\hline
\end{tabular}

\section{RESULTS AND DISCUSSION}

\section{Macroscopic Parameters and Structure}

The application of Additive Manufacturing through piston deposition using 3D printing head created specimens by layers similar to FDM (Fused Deposition Modeling), but using a cold process (Figure 1(b)). The layered manufacturing generates an asymmetric structure which increases the mechanical strength of the specimens (Figure 3).

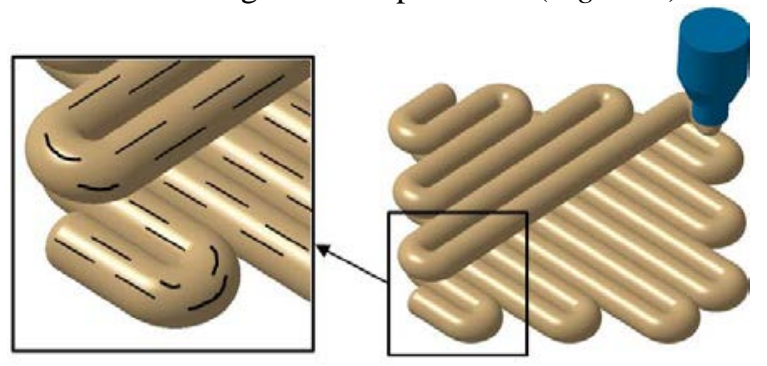

FIGURE 3. Deposition wood pulp and fibers strengthening. 
The orientation of each superimposed threads has an angle of $90^{\circ}$ in AM. This interaction among the fibers improves the stiffness and strength of the specimen. However, due to the orientation of filaments and fibers in each layer, the resulting mechanical properties can differ in the three directions. The vertical direction $\mathrm{Z}$ to the layered plane has the lowest properties. The thread superposition should not be masked by following the microscopic study.

\section{Microscopic Structure}

The influence of material and process parameters on the microstructure was determined. The fibers are oriented according to the Additive Manufacturing process and have an angle that varied with the morphology that develops during the deposit extrusion and solidification. The influence of the following process variables on fiber morphology was examined:

1) Extrusion speed of the piston system (controlled by computer)

2) Average beech flour fiber size ranging from 40 to $120 \mu \mathrm{m}$

3) Viscosity of the starch matrix.

The microstructure and fiber orientation of the wood filaments and fibers were observed using an optical microscope (Figure 4(a)). The structure is generally dominated by fibers oriented toward the extrusion direction. Some fibers are set at various angles but never in the direction perpendicular to thread. Furthermore, following the withdrawal of starch during drying fibers consolidate into a heterogeneous mass. The drying causes the starch to stick the filaments to each other and some fibers intercalate at the junction. The mixture obtained by the DOE is heterogeneous between beech flour and starch. Drying starch has a strong influence on the final structure. The solidification behavior as illustrated in Figure 4 showed the filament diameter was $2 \mathrm{~mm}$ out of the nozzle and $1.2 \mathrm{~mm}$ after cooling. Thus the draw down is $40 \%$ in the radial direction.

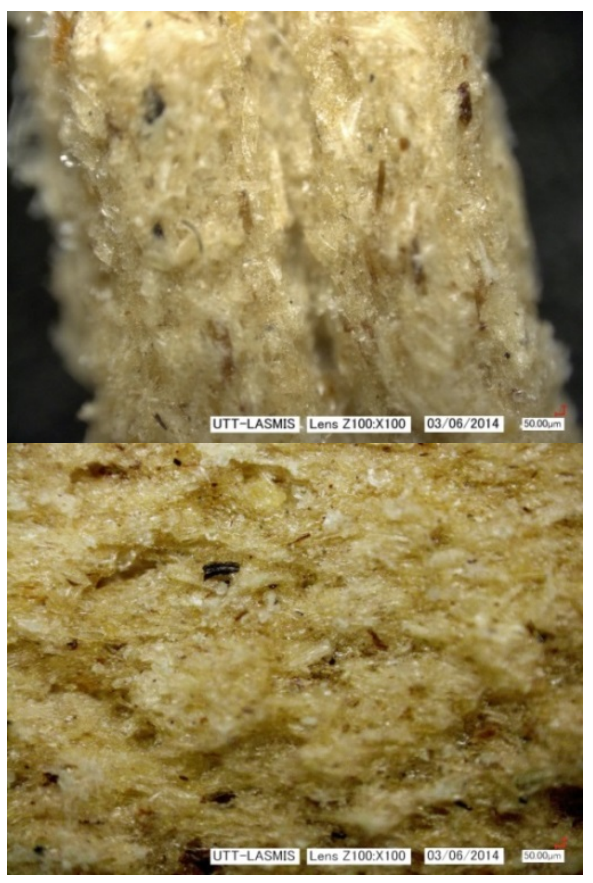

FIGURE 4. Microstructure of two wood filaments (a) and fibers size (50 $\mu \mathrm{m}$ scale $X 100$ ) (b).

An electronic microscope at a $50 \mu \mathrm{m}$ scale was used to measure fiber lengths. Fiber lengths ranging between $50 \mu \mathrm{m}$ to $150 \mu \mathrm{m}$ length were found (Figure 4(b)). Since the starch serves as a binder, further characterization of the interactions between the filaments and starch will be required to completely understand the filament microstructure.

\section{Filament Characterization}

Tensile testing was undertaken to characterize the mechanical properties of wood filaments. The tests were carried on filament lengths $\mathrm{L}_{\mathrm{i}}(i=\overline{1-4})$ of 11 mm. A micro-tensile test machine Kammrath \& Weiss (Figure 5) was used to carry out uniaxial tensile tests using the the method proposed by Florent Ilczyszyn [19]. The displacement speed of the machine was $1 \mu \mathrm{m} . \mathrm{s}-1$ with a sampling period of $500 \mathrm{~m} . \mathrm{s}-1$. The load cell capability is $100 \mathrm{~N}$ with an uncertainty of $1 / 100 \mathrm{~N}$. 
(a)

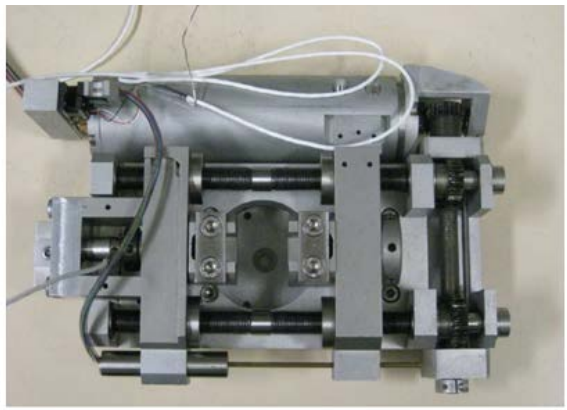

(b)

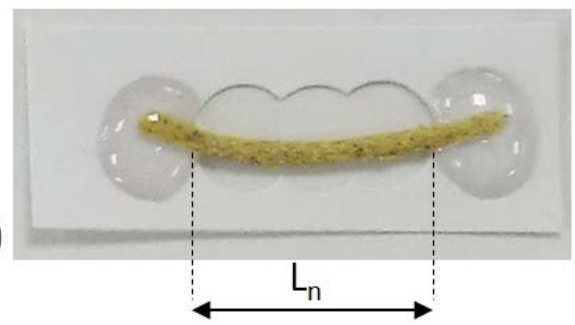

FIGURE 5. Photo of the micro-tensile test machine (a) and filament support (b) according to [19].

The filament is glued on a paper with a gap to support the filament's tops, avail a test length and protect the extremities from damage when tightening the grips. Glue points at both ends of specimen to keep the filament on the support. The method focuses on a circular and constant cross section along the filament. The stress (o) across a filament with a circular cross section $\left(S_{\text {circular }}\right)$ is based on the equation used by S. Ralf [20], where F is applied force.

$$
\sigma=\frac{\mathrm{F}}{\mathrm{S}_{\text {circular }}}
$$

The wood filaments exhibit fragile behavior with sudden rupture. However, in some cases, there is a partial resistance of wood filament after the maximum force reached (Figure 6). The cause is that the filament is not perfectly straight. The cross section of wood filaments $(\mathrm{d}=1.2 \mathrm{~mm})$ is $1.13 \mathrm{~mm}^{2}$. The tensile properties of all specimens are presented in Figure IV. The maximum tensile load of 4 tested specimens doesn't rise above $8 \mathrm{~N}$ and the longitudinal displacement varies from 100 to $200 \mu \mathrm{m}$. The tensile strain average of $1.25 \%$ indicates the wood filaments are quite brittle. The maximum tensile stress and Young's modulus values (from Hooke's Law) are 7.03 $\mathrm{MPa}$ and $728.58 \mathrm{MPa}$ respectively. Figure 7 presents the tensile strength evolution versus tensile strain. Before the maximum stress reached, the filament behavior is quasi-linear. After the initial yield point, the tensile stress increases at a much lower rate until filament rupture.
In the cases of curves $\mathrm{L}_{3}$ and $\mathrm{L}_{4}$, the stress reduction is caused by filament cross section loss.

The differences in the failure mechanism observed are most likely a result of differences in filament to filament crystallinity and indicative of a good deal of heterogeneity in the morphology.

In this study, the number of tensile tests is limited to four. A future in-depth study with more tests is desirable in order to better understand the mechanical behavior of the wood filaments and to have a more statistically significant result.

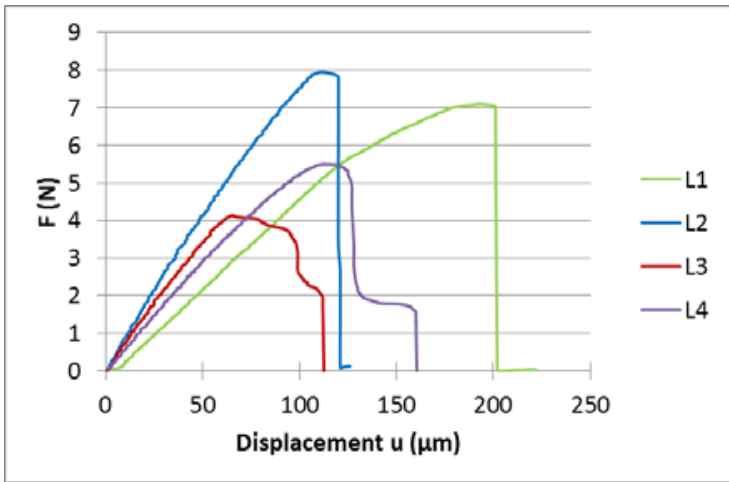

FIGURE 6. Tensile force versus displacement $(\mu \mathrm{m})$. There are two types of behavior: the fragile behavior with sudden rupture (the blue and the green curve) and the behavior with partial resistance of the wood filament after the initial yield (the red curve and the violet curve).

TABLE IV. Mechanical properties of wood filament.

\begin{tabular}{|c|c|c|c|}
\hline Specimen & $\begin{array}{c}\text { Tensile } \\
\text { strain (\%) }\end{array}$ & $\begin{array}{c}\text { Tensile } \\
\text { strength } \\
(\mathrm{MPa})\end{array}$ & $\begin{array}{c}\text { Young's } \\
\text { modulus } \\
(\mathrm{MPa})\end{array}$ \\
\hline $\mathrm{L}_{1}$ & 1.84 & 6.27 & 468.23 \\
\hline $\mathrm{L}_{2}$ & 1.09 & 7.03 & 728.58 \\
\hline $\mathrm{L}_{3}$ & 0.9 & 3.66 & 640.69 \\
\hline $\mathrm{L}_{4}$ & 1.15 & 4.86 & 562.86 \\
\hline Average & 1.25 & 5.45 & 600.09 \\
\hline Deviation & 0.36 & 1.3 & 96.09 \\
\hline
\end{tabular}




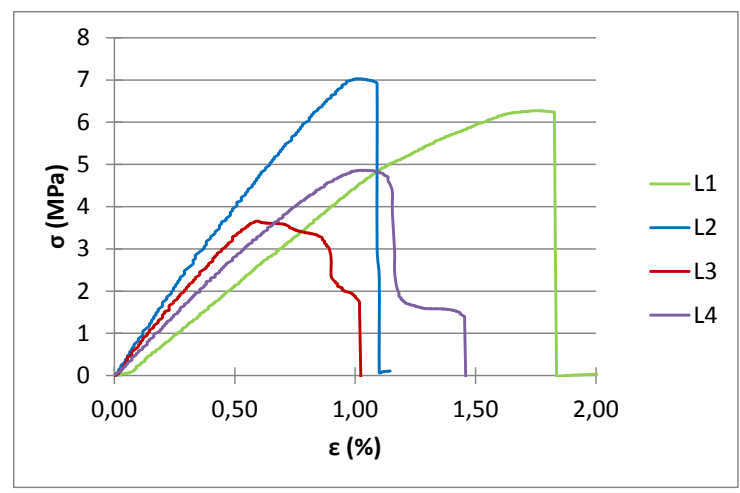

FIGURE 7. Tensile stress versus tensile strain (\%).

\section{Matrix Structure}

It is well documented that the mechanical properties of composite materials depend strongly on the coupling between the fibers and the matrix at the interface- a weak interface decreases the composite strength [21]. Chemically modified starches develop viscosity and binding properties at low temperature or at normal heat temperatures in a water-limited environment. One characteristic of starch is that its granules attached to each other and form larger granules. Gelatinized starch is a viscous adhesive. The mixture of starch and wood flour created a composite of fibers. The starch wraps the beech flour and agglomerates the fibers during cooling as shown in the electron micrographs in Figure 8. The starch structure (shiny appearance) is generally present over the entire surface. In a composite, it is the relative amount of cohesion of the matrix and reinforcing medium affects the overall properties. Based on observation of the properties obtained, the adhesion between the wood fibers and the matrix appears to be similar that of a nonwoven composite.

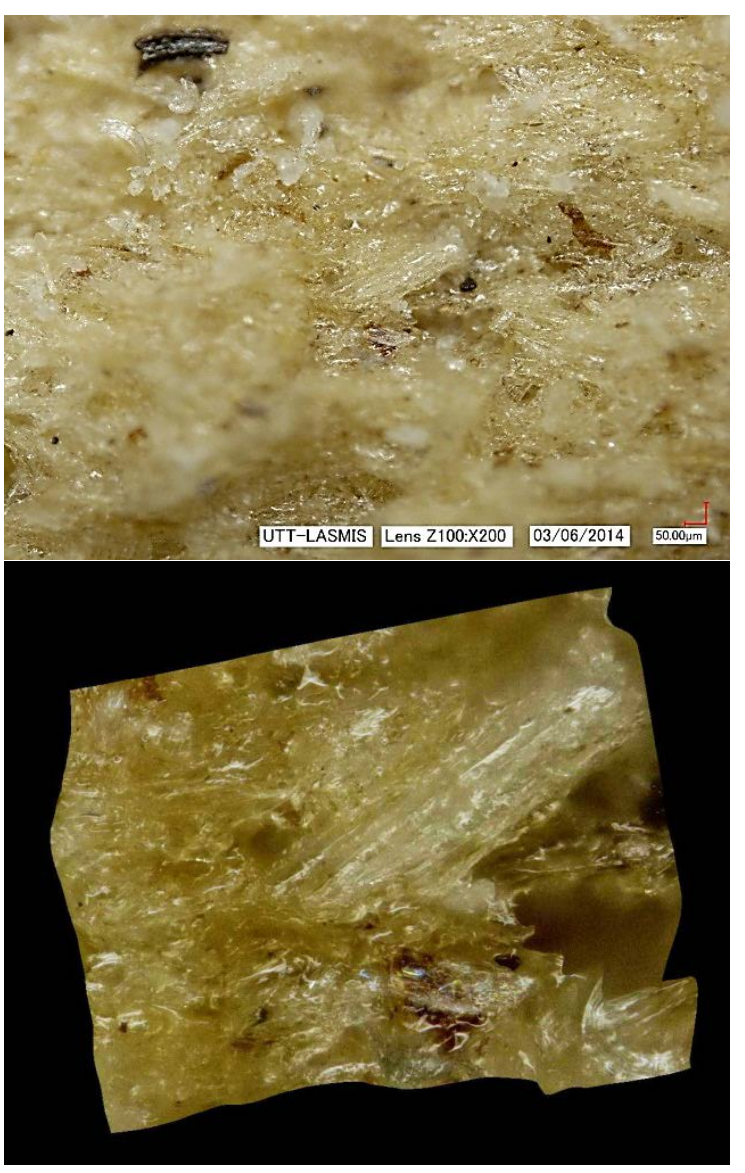

FIGURE 8. Starch matrix structure and 3D representation (50 $\mu \mathrm{m}$ scale X 200).

\section{CONCLUSION}

The structure of wood composite manufactured by additive manufacturing has been characterized at macro and microscopic levels. Microscopic examination indicates agglomeration of the wood flour and adhesion to the incorporated wood fibers. The processing parameters have an influence on the mechanical and physical properties of the structure. The experiments reveal fundamental microstructure and process characteristics:

1) The macroscopic structure shows a fiber strengthening via multilayer intercalation within the matrix.

2) The microscopic structure of filament is a nonwoven composite with fibers oriented in the extrusion direction. 
Individual filament tensile strength strain average 5.45 $\mathrm{MPa}$ and $1.25 \%$ respectively with a Young's modulus of $600.09 \mathrm{MPa}$. The filament are relatively it with a tensile strength $25 \mathrm{MPa}$ of polypropylene composite filled with $40 \%$ wood floor and a young' modulus of $3.5 \mathrm{GPa}$ [22]. The strength properties are limited by the heterogeneous nature of the wood fiber morphology and sensitivity of the material to ambient conditions with its humidity uptake and shrinkage on cooling. Humidity uptake is due to the hydrophilic properties of hemicellulose and starch.

\section{REFERENCES}

[1] Gardan, J, Rapid prototyping system of an object by material extrusion - Système de prototypage rapide d'un objet par extrusion de matière, FR 3002179 (A1), 2014. http://fr.espacenet.com/publicationDetails/bib lio?FT $=$ D\&date $=20140822 \& D B=$ fr.espacene t.com\&locale $=$ fr_FR\&CC $=$ FR \&NR $=300217$ $9 \mathrm{~A} 1 \& \mathrm{KC}=\mathrm{A} 1$.

[2] J. Gardan, Additive manufacturing technologies: state of the art and trends, International Journal of Production Research. 0 $1-15$. doi:10.1080/00207543.2015.1115909.

[3] A. Bernard, A. Fischer, New Trends in Rapid Product Development, CIRP Annals Manufacturing Technology. 51 (2002) 635652. doi:10.1016/S0007-8506(07)61704-1.

[4] J.-C. Sagot, V. Gouin, S. Gomes, Ergonomics in product design: safety factor, Safety Science. 41 (2003) 137-154.

[5] Gardan, J, Roucoules, L, Characterization of beech wood pulp towards sustainable rapid prototyping, International Journal of Rapid Manufacturing (IJRapidM), Inderscience. 2 (2011) 215-233. doi:10.1504/IJRAPIDM.2011.044700.

[6] N. Hopkinson, P. Dickens, Rapid prototyping for direct manufacture, Rapid Prototyping Journal. 7 (2001) 197-202.

[7] E. Malone, H. Lipson, Fab@Home: the personal desktop fabricator kit, Mechanical and Aerospace Engineering, Cornell University, Rapid Prototyping Journal. Emerald Group Publishing (2007).
[8] S.S. Crump, Apparatus and method for creating three-dimensional objects, Google Patents, 1992.

http://www.google.com/patents/US5121329 (accessed December 17, 2014).

[9] S.S. Crump, Modeling apparatus for threedimensional objects, Google Patents, 1994. http://www.google.com/patents/US5340433 (accessed December 17, 2014).

[10] G. Vozzi, A. Previti, D. De Rossi, A. Ahluwalia, Microsyringe-based deposition of two-dimensional and three-dimensional polymer scaffolds with a well-defined geometry for application to tissue engineering, Tissue Engineering. 8 (2002) 1089-1098.

[11] S.-H. Ahn, M. Montero, D. Odell, S. Roundy, P.K. Wright, Anisotropic material properties of fused deposition modeling ABS, Rapid Prototyping Journal. 8 (2002) 248-257.

[12] Kaufui V.Wong; Aldo Hernandez, A Review of Additive Manufacturing, International Scholarly Research Network. (2012).

[13] J. de Ciurana, L. Serenóa, È. Vallès, Selecting Process Parameters in RepRap Additive Manufacturing System for PLA Scaffolds Manufacture, Procedia CIRP. 5 (2013) 152-157. doi:10.1016/j.procir.2013.01.031.

[14] T. Serra, J.A. Planell, M. Navarro, Highresolution PLA-based composite scaffolds via 3-D printing technology, Acta Biomaterialia. 9 (2013) 5521-5530. doi:10.1016/j.actbio.2012.10.041.

[15] Y. Yan, S. Li, R. Zhang, F. Lin, R. Wu, Q. Lu, et al., Rapid Prototyping and Manufacturing Technology: Principle, Representative Technics, Applications, and Development Trends, Tsinghua Science \& Technology. 14, Supplement 1 (2009) 1-12. doi:10.1016/S1007-0214(09)70059-8.

[16] R.B. Miller, Structure of wood, Wood Handbook: Wood as an Engineering Material. Madison, WI : USDA Forest service, Forest Products Laboratory (1999) 2.1-2.4. 
[17] L. Condra, Reliability Improvement with Design of Experiment, Second Edition, 2 edition, CRC Press, New York, 2001.

[18] Wu C.J., Hamada M.S., Experiments : Planning, Analysis, And Parameter Design Optimization, Second edition, Willey, 2009.

[19] F. Ilczyszyn, A. Cherouat, G. Montay, Effect of hemp fibre morphology on the mechanical properties of vegetal fibre composite material, in: Advanced Materials Research, Trans Tech Publ, 2014: pp. 485-489. http://www.scientific.net/AMR.875-877.485 (accessed November 19, 2015).

[20] S. Ralf, M. Luisa, K. Schlarb Alois, Mechanical and morphological characterization of selected natural fibres, Advanced Composites Letters. 15 (2006) 55-61.

[21] D.C. Nguyen, A. Makke, G. Montay, A Pull-out Fiber/Matrix Interface Characterization of Vegetal Fibers Reinforced Thermoplastic Polymer Composites: The Influence of the Processing Temperature, (n.d.). http://www.researchgate.net/profile/Duy_Cuo ng_Nguyen2/publication/282669965_A_Pullout_FiberMatrix_Interface_Characterization_ of_Vegetal_Fibers_Reinforced_Thermoplasti c_Polymer_Composites_The_Influence_of_t he_Processing_Temperature/links/5617c8490 8ae4780f241e04f.pdf (accessed November 19, 2015).

[22] N.M. Stark, R.E. Rowlands, Effects of wood fiber characteristics on mechanical properties of wood/polypropylene composites, Wood and Fiber Science. 35 (2007) 167-174.

[23] J. Hiller, H. Lipson, STL 2.0: A Proposal for a Universal Multi-Material Additive Manufacturing File Format, in: Proc. Solid Freeform Fabrication Symposium (SFF'09), Austin, Texas, 2009: pp. 266278.http://utwired.engr.utexas.edu/lff/sympos ium/proceedingsArchive/pubs/Manuscripts/2 009/2009-23-Hiller.pdf (accessed February 16, 2014).

\author{
AUTHORS’ ADDRESSES \\ Julien Gardan \\ EPF, Engineering School \\ 2, Fernand SASTRE \\ 10430 Rosière-Près-Troyes \\ FRANCE
}

ICD/LASMIS, UMR CNRS 6281

University of Technology of Troyes

12 rue Marie Curie

BP2060 10010 Troyes

FRANCE

\section{Duy Cuong Nguyen, PhD \\ Guillaume Montay}

ICD/LASMIS, UMR CNRS 6281

University of Technology of Troyes

12 rue Marie Curie

BP2060 10010 Troyes

FRANCE

\section{Lionel Roucoules}

Arts et Métiers Paris Tech

CNRS, LSIS,

2 cours des Arts et Métiers

13617 Aix-En-Provence

FRANCE 